\title{
Article
}

\section{Adopting evidence-based guidelines for acute stroke care: barriers and enablers for health professionals}

Harrison, Joanna, Timoroksa, Anne-Marie, Gregary, Bindu and Hill, James Edward

Available at http://clok.uclan.ac.uk/31904/

Harrison, Joanna ORCID: 0000-0001-8963-7240, Timoroksa, Anne-Marie, Gregary, Bindu and Hill, James Edward (2020) Adopting evidence-based guidelines for acute stroke care: barriers and enablers for health professionals. British Journal of Neuroscience Nursing, 16 (1). ISSN 1747-0307

It is advisable to refer to the publisher's version if you intend to cite from the work. 10.12968/bjnn.2020.16.1.8

For more information about UCLan's research in this area go to http://www.uclan.ac.uk/researchgroups/ and search for <name of research Group>.

For information about Research generally at UCLan please go to http://www.uclan.ac.uk/research/

All outputs in CLoK are protected by Intellectual Property Rights law, including Copyright law. Copyright, IPR and Moral Rights for the works on this site are retained by the individual authors and/or other copyright owners. Terms and conditions for use of this material are defined in the policies page.

\section{CLoK}

Central Lancashire online Knowledge www.clok.uclan.ac.uk

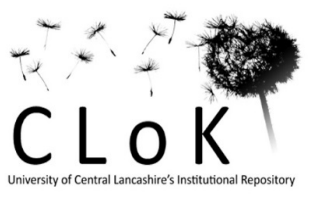




\section{Commentary: "Adopting evidence-based guidelines for acute stroke care: barriers and enablers for health professionals"}

An evidence summary based on the following systematic review: Baatiema, L., Otim, M.E., Mnatzaganian, G., deGraft Aikins, A., Coombes, J. \& Somerset, S. (2017) 'Health professionals' views on the barriers and enablers to evidence-based practice for acute stroke care: a systematic review'. Implementation Science, 12(1):74

\section{Introduction}

Evidence-based practice is the keystone of clinical practice, policy and management (Lehane et al. 2019). Despite this, a knowledge to practice gap still exists and it is estimated to take 17 years for evidence to be translated to clinical practice (Morris et al. 2011). The reasons for slow translation in acute stroke care are not completely understood. Some studies have highlighted the barriers that result in under-utilisation of best practice (Baker et al. 2010; Grimshaw et al. 2012). However, no previous review has attempted to systematically analyse barriers and enablers within the highly recommended acute stroke therapies (Baatiema et al. 2017). A systematic review by Baatiema et al. (2017) addressed this issue by exploring the adoption of evidence-based guidelines for acute stroke, through the views of health professionals. The aim of this review was to identify and systematically review studies of health professionals' views on the barriers and enablers to evidence-based interventions for acute stroke care.

\section{Aims of the commentary}

This commentary aims to critically appraise the methods used within this review and expand upon the findings in context to clinical practice.

The review

The review authors searched for peer-reviewed studies of any kind that identified barriers or enablers to the uptake of four highly recommended acute stroke therapies or services: specialist stroke unit care, thrombolytic therapy, the use of aspirin and de-compressive surgery. Relevant healthcare databases were searched for eligible studies published from 1990-2016. Included studies were based on the views and experiences of health professionals (stroke

\section{KEY POINTS}

- Organisational context or structural level factors were the most frequent barriers to uptake of evidence-based care for acute stroke.

- Poor understanding of barriers or enablers to uptake of guidelines means that effective therapies are underutilised.

- Future interventions/health policy should utilise these findings to encourage uptake of best practice.

specialists, medical doctors, nurses, allied health professionals and health managers, health planners, health policy-makers or any health executives) and were limited to studies that were peer-reviewed and published in English. The barriers and facilitators for evidence-based interventions had to relate to decompressive surgery, thrombolytic therapy, aspirin, decompressive surgery and care in a stroke unit.

Quality assessment was carried out by two independent reviewers using the Joanna Briggs Institute tool for assessing qualitative studies and the Centre for Evidence-Based Management appraisal tool for quantitative studies.

Analysis of studies was conducted using both descriptive statistics (quantitative studies) and thematic analysis (qualitative studies). A preexisting framework of seven domains (Flottorp et al. 2013) was used to categorise the themes of barriers and enablers. The key findings were identified by one author, categorised using the framework and validated by a second author.

\section{Quality of the review}

Using the Joanna Briggs Institute Critical Appraisal tool for systematic reviews 9 out of the 11 criteria 
were satisfactory (The Joanna Briggs Institute. 2017). It was deemed that assessment of publication bias was not applicable in this review and the methods to minimise error in data extraction were not adequate. As both screening and data extraction were carried out by a single reviewer. With the screening process being verified by a second reviewer. Despite this these methods are susceptible to miss relevant studies (Waffenschmidt et al. 2019) and introduce error in data extraction (Buscemi et al. 2006).

Based on this quality assessment of this review it was deemed that the systematic review may provide an accurate summary of the results of the available studies that were included in the review.

\section{Quality of included studies}

Methodological limitations were found in the quantitative studies such as a lack of detail on sampling techniques. This lack of detail of the sampling technique of the included studies makes it difficult to evaluate the generalisability of the included quantitative studies (Elfil and Negida 2017) and introduces selection bias (Hegedus and Moody 2010). The overall quality of the quantitative studies was classified as moderate using the Centre for Evidence-Based Management appraisal tool.

The quality of qualitative studies was uncertain. Authors reported how data collection was adequately described, however, none of the studies reported on theoretical or philosophical sources for methodological relevance, analysis and interpretation.

\section{Main review findings}

Overall 10 studies met the inclusion criteria (three qualitative and seven quantitative). Studies were published between 2004 and 2015 and conducted in Australia, USA, Sweden, Norway, Denmark and the Netherlands. The total number of participants was 1692 and included nurses, doctors, neurologists, emergency department physicians, allied health staff and health managers.
Table.1 shows the frequency (\%) of each theme based on the number of times relevant barriers and enablers were reported in the eligible studies. Social, political and legal factors were not reported.

Table.1 Barriers or enablers to adopting evidencebased acute stroke care

\begin{tabular}{|c|c|}
\hline Theme & Barrier or Enabler \\
\hline $\begin{array}{l}\text { Capacity for } \\
\text { organisational } \\
\text { change (37\%) }\end{array}$ & $\begin{array}{l}\text { - Lack of institutional support, e.g. } \\
\text { lack of guidelines, funding for } \\
\text { professional development. } \\
\text { - Limited health staff capacity, e.g. } \\
\text { shortage of stroke nurses. } \\
\text { - Workload demands and a lack of } \\
\text { protocols. }\end{array}$ \\
\hline $\begin{array}{l}\text { Individual } \\
\text { health } \\
\text { professionals' } \\
\text { factors (25\%) }\end{array}$ & $\begin{array}{l}\text { - Lack of awareness/knowledge of } \\
\text { an intervention. } \\
\text { - Lack of skills to apply the } \\
\text { intervention. } \\
\text { - Low motivation to implement. }\end{array}$ \\
\hline $\begin{array}{l}\text { Resources } \\
\text { and } \\
\text { incentives } \\
(11 \%)\end{array}$ & $\begin{array}{l}\text { - Limited physical space to establish } \\
\text { stroke units. } \\
\text { - Lack of CT scans and financial } \\
\text { resources. } \\
\text { - Limited time, stroke beds and staff } \\
\text { capacity. }\end{array}$ \\
\hline $\begin{array}{l}\text { Guideline } \\
\text { factors (10\%) }\end{array}$ & $\begin{array}{l}\text { - The nature of evidence related to } \\
\text { stroke guidelines could influence } \\
\text { uptake amongst health } \\
\text { professionals, e.g. perceptions of } \\
\text { the effectiveness of thrombolysis. }\end{array}$ \\
\hline $\begin{array}{l}\text { Patient } \\
\text { factors (10\%) }\end{array}$ & $\begin{array}{l}\text { - Lack of awareness of early stroke } \\
\text { symptoms. } \\
\text { - Patients arriving late in emergency } \\
\text { departments to receive } \\
\text { care/thrombolysis. } \\
\text { - Patient's decision for other } \\
\text { interventions (due to perceived } \\
\text { side-effects of thrombolysis). }\end{array}$ \\
\hline $\begin{array}{l}\text { Professional } \\
\text { Interactions } \\
(7 \%)\end{array}$ & $\begin{array}{l}\text { - Inadequate communication } \\
\text { between clinical staff. } \\
\text { - Lack of clinical leadership/ } \\
\text { support from senior clinicians. }\end{array}$ \\
\hline
\end{tabular}

The main limitations of the review

The review process may have missed relevant articles due to the inclusion criteria (English language/ peer-reviewed articles). Only ten studies were identified to be included in this review. However, the authors report that there seemed to be a saturation of potential determinants due to the commonality of the barriers and enablers given within the included studies. The authors also acknowledge that using a pre-defined framework to organise the findings may inadvertently exclude some barriers/enablers. 
This was an international review with authors from Ghana, Australia and UAE. The primary author was from the University of Ghana. The review was published in Implementation Science which has an impact factor of 4.525 (within the top 12\% of journals).

\section{Implications for practice and research}

The most cited barriers from the review are organisational context or structural level factors. Given the significance of these findings (and reference in other reviews), health managers and policy makers should consider addressing these barriers. Based on the barriers identified in this review specific focus should be given to current institutional support such as developing guidelines and funding opportunities for staff development.

At the level of the individual healthcare professional there is a perception of lack of adequate health resources, medical facilities and lack of skills to apply the intervention. Therefore, to overcome these barriers it is essential to ensure that the environment, resources and the staff's domain knowledge are adequate to ensure the optimal uptake of evidence-based practice. The review identifies that health professionals have their own unique challenges to adopting evidence that future research should explore further.

The findings also highlighted delays in patients arriving at hospital due to non-recognition of stroke symptoms. The authors therefore recommend the need for increased public health campaigns and further research for seeking care during early onset of stroke symptoms.

This report is independent research funded by the National Institute for Health Research Applied Research Collaboration North West Coast (ARC NWC). The views expressed in this publication are those of the author(s) and not necessarily those of the National Institute for Health Research or the Department of Health and Social Care.

11 | Collaboration for Leadership in Applied Health Research and Care North West Coast

\section{References}

Baker R, Camosso-Stefinovic J, Gillies C, Shaw EJ, Cheater F, Flottorp S, Robertson N. 2010. Tailored interventions to overcome identified barriers to change: effects on professional practice and health care outcomes. Cochrane Database Syst Rev.(3):CD005470.

Burke F, Hayes M et al. 2019. Evidence-based practice education for healthcare professions: an expert view. BMJ Evidence-Based Medicine. 24(3):103.

Buscemi N, artling L, Vandermeer B, Tjosvold L, Klassen TP. 2006. Single data extraction generated more errors than double data extraction in systematic reviews. Journal of Clinical Epidemiology. 59(7):697-703.

Donnellan C,Sweetman S, Shelley E. 2013. Health professionals' adherence to stroke clinical guidelines: a review of the literature. Health Policy. 111(3):245-263

Flottorp SA, Oxman AD, Krause J, Musila NR, Wensing $M$,

Godycki-Cwirk M, Baker R, Eccles MP. 2013. A checklist for identifying determinants of practice: $A$ systematic review and synthesis of frameworks and taxonomies of factors that prevent or enable improvements in healthcare professional practice. Implementation Science. 8(1):35.Elfil M, Negida A. 2017. Sampling methods in Clinical Research; an Educational Review. Emerg (Tehran). 5(1):e52-e52. eng.

Hegedus EJ, Moody J. 2010. Clinimetrics corner: the many faces of selection bias. J Man Manip Ther. 18(2):69-73. Eng.

Grimshaw JM, Eccles MP, Lavis JN, Hill SJ, Squires JE. 2012. Knowledge translation of research findings. Implement Sci. 7:50.

Lehane E, Leahy-Warren P, O'Riordan C, Savage E, Drennan J, O'Tuathaigh C, O'Connor M, Corrigan M, Morris ZS, Wooding S, Grant J. 2011. The answer is 17 years, what is the question: understanding time lags in translational research. J R Soc Med. 104(12):510-520. eng.

Waffenschmidt S, Knelangen M, Sieben W, Buhn S, Pieper D. 2019. Single screening versus conventional double screening for study selection in systematic reviews: a methodological systematic review. BMC Med Res Methodol. 19(1):132. 